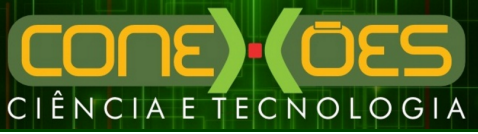

\title{
INFLUÊNCIA DE UM PROJETO NÃO GOVERNAMENTAL NA EDUCAÇÃO AMBIENTAL FORMAL E INFORMAL: O CASO DO PROJETO ALGAS, CULTIVANDO SUSTENTABILIDADE
}

\author{
Emanoel Rodrigues Moura ${ }^{1}$, Cristiane MARia SAMPaio Forte $^{2}$, \\ ANDRÉA PEREIRA SILVEIRA ${ }^{3}$ \\ ${ }^{1,2}$ Faculdade de Educação de Itapipoca, Universidade Estadual do Ceará (FACEDI-UECE) \\ Curso de Licenciatura em Química \\ ${ }^{3}$ Faculdade de Educação de Itapipoca, Universidade Estadual do Ceará (FACEDI-UECE)
}

Curso de Licenciatura em Ciências Biológicas

<emanoel.rm@gmail.com>, <cristiane.forte@uece.br>, <andrea.silveira@uece.br>

DOI: $10.21439 /$ conexoes.v11i4.955

\begin{abstract}
Resumo. Ações de Educação Ambiental formal e informal não são mutuamente excludentes, embora na prática predominem abordagens segregadas. Por isso, nosso objetivo foi saber se um projeto não governamental de atividades sustentáveis e com fundamentos na educação ambiental influencia na sensibilização ambiental de estudantes da escola local. Nossa hipótese é que os alunos da Escola Fortunato Severiano da Costa (Escola B -EB), situada na comunidade de Flecheiras local de desenvolvimento do projeto "Algas: Cultivando Sustentabilidade", são mais sensíveis a questão ambiental do que os alunos da escola Raimundo Nonato Ribeiro (Escola A - EA), situada na sede do município de Trairi-Ceará, onde não existe nenhum projeto com estas qualificações. Selecionamos 35 alunos da EA e 33 alunos da EB, das turmas de $3^{\circ}$ ano do ensino médio para este estudo de caso. Utilizamos um questionário com 13 questões objetivas divididas em três tópicos: hábito diário, consumo responsável e conhecimentos ambientais. Diferente do esperado, não registramos uma sensibilização superior dos alunos da EB em relação aos alunos da EA, pois as porcentagens das respostas elencancas nos três tópicos foram semelhantes. Essa semelhança pode i) ser resultado de um trabalho de conscientização escolar superior na EA, visto que $69 \%$ dos alunos obtem informações ambientais na EA, em comparação com os 38\% da EB e/ou ii) ser reflexo de uma abrangência do projeto algas fora dos limites da comunidade. As duas explicações são plausíveis e devem atuar conjuntamente, resultando em níveis de sensibilização ambiental elevados e semelhantes entre os alunos das duas escolas investigadas.
\end{abstract}

Palavras-chaves: Educação Ambiental. Cultivo de Algas. Meio Ambiente. Hábitos sustentáveis.

\begin{abstract}
Environmental Education actions formal and informal are not mutually exclusive, although in practice it approaches are prevalent segregated. Therefore, our goal was to find out if a non-governmental project of sustainable activities and bases in environmental education influence the environmental awareness of students from the local school. Our assumption is that students of the school Fortunato Severiano da Costa (B School-BS), located at place Flecheiras community, development project "Algae: Cultivating Sustainability", have environmental awareness higher than the students of the school Raimundo Nonato Ribeiro (A School-AS), located at the headquarters of the municipality of Trairi, Ceará, where there is no project with these qualifications. We selected 35 students from AS and 33 students from BS from the 3rd year of high school for this case of study. We used a questionnaire with 13 objective questions divided into three topics: daily habit, responsible consumption and environmental knowledge. Different than expected, did not record a higher awareness of BS's students compared to students from AS, as the percentages of responses in three topics were similar. This similarity can be explained by i) the result of a higher school awareness work at AS, as $69 \%$ of students get environmental information in the AS, compared to $38 \%$ of the BS and / or ii) be a reflex of a scope of the project algae outside the community borders. Both explanations are acceptable and must act together, resulting in high levels of environmental awareness and similar between students of the two schools surveyed.
\end{abstract}

Keywords: Environmental Education. Algae cultivation. Environmental. Sustainable habits. 


\section{INTRODUÇÃO}

O termo Educação Ambiental surge na Inglaterra, no ano de 1965, em uma conferência da Universidade de Keele, com o intuito de dar um enfoque educativo e interdisciplinar às ciências naturais e sociais (KIST 2010). No Brasil as organizações não governamentais (ONGs), foram as grandes protagonistas na luta pelas questões ambientais a partir da década de 1970, mas foi a partir de 1992, com a Rio-92 que a temática ambiental ganhou maiores repercursões (MATOS, 2009). A partir de então a Educação Ambiental tem sido apontada como uma possibilidade de reflexões cotidianas, sendo considerada a forma mais direta de abordar assuntos vitais para o estabelecimento de costumes e práticas embasadas na sensibilização ambiental (MANO; PACHECO; BENELLI, 2010; LUCCA; BRUM, 2013).

Por isso é atribuída a Educação Ambiental o dever de preparar o indivíduo para a compreensão dos principais problemas ambientais do mundo contemporâneo, com vistas a melhorar a vida e proteger o meio ambiente, prestando a devida atenção aos valores éticos (PASSOS et al., 2014). A Educação Ambiental no âmbito escolar deve ser pautada em uma prática sintonizada com a vida da sociedade, com o comportamento do homem, sua relação com o meio ambiente, suas habilidades e suas percepções (COSTA; COSTA, 2011). Além disso, o principal desafio da Educação Ambiental escolarizada é que ela deixe de ser algo realizado e praticado a parte e passe a ser um eixo integrador do ensino de ciências (WOLLMANN; SOARES; ILHA, 2015).

A Constituição Federal de 1988, em seu artigo 225, inciso VI, reconhece a responsabilidade individual e coletiva da sociedade na implementação e prática da educação ambiental, e estabelece que cabe ao poder público promover a Educação Ambiental em todos os níveis de ensino (BRASIL, 2000). A Política Nacional de Educação Ambiental (PNEA) estabelece que a Educação Ambiental deva estar presente de forma articulada em todos os níveis, bem como, modalidades do sistema educativo e, diz em seu Art. $1^{\circ}$ que,

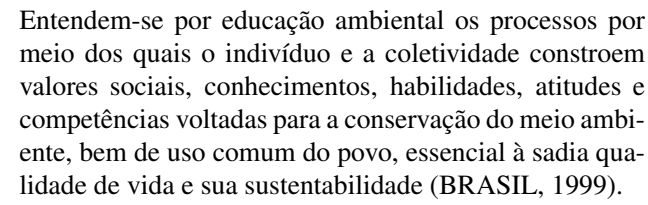

Entendem-se por educação ambiental os processos por meio dos quais o indivíduo e a coletividade constroem valores sociais, conhecimentos, habilidades, atitudes e competências voltadas para a conservação do meio ambiente, bem de uso comum do povo, essencial à sadia qualidade de vida e sua sustentabilidade (BRASIL, 1999).

Fica claro que as ações de Educação Ambiental podem ser trabalhadas tanto no ensino formal, praticado dentro e fora dos limites escolares e inserida no currículo, como no contexto informal, não restrita ao ambiente escolar e envolvendo a comunidade local (REIS;
SEMÊDO; GOMES, 2012). Essas duas vertentes não são mutuamente excludentes, mas na prática o que predomina são as abordagens segregadas. Mas, o quanto a Educação Ambiental informal influencia a Educação Ambiental formal e vice-versa é uma questão que merece ser discutida. Nesse contexto, surgiu a questão norteadora desta investigação que busca saber se: Um projeto não governamental de atividades sustentáveis e com fundamentos na educação ambiental influencia na sensibilização ambiental de estudantes da escola local?

Para responder a este questionamento temos por objetivo analisar a sensibilização ambiental de estudantes do $3^{\circ}$ ano do Ensino Médio de duas escolas, uma com influência direta de um projeto não governamental intitulado "Algas: Cultivando Sustentabilidade" e outra fora da área de abrangência do projeto. As duas escolas são: Escola de Ensino Médio Raimundo Nonato Ribeiro (EA) situada na sede do município de TrairiCeará, fora da área de abrangência do projeto e Escola de Ensino Médio Fortunato Severiano da Costa (EB) situada na comunidade praiana de Flecheira, município de Trairi-Ceará, que abriga o projeto "Algas: Cultivando Sustentabilidade".

O projeto "Algas: Cultivando Sustentabilidade" é uma iniciativa dos moradores das comunidades praianas de Flecheiras e Grajirú, situadas no município de Trairi, estado de Ceará, que mantém junto às atividades de cultivos e processamento de algas marinhas um centro de Educação Ambiental. O referido centro foi fundado em 2002 quando o Instituto Terramar (uma organização não governamental) estabeleceu parceria com um grupo de moradores.

Nossa hipótese é que os alunos da escola Fortunato Severiano da Costa (Escola B - EB) situada na comunidade praiana de Flecheira local de desenvolvimento do projeto "Algas: Cultivando Sustentabilidade", possuem maior sensibilização em relação às questões ambientais como hábitos saudáveis e consumo responsável, quando comparados aos alunos da escola Raimundo Nonato Ribeiro (Escola A - EA), situada na sede do município de Trairi-Ceará, onde não existe nenhum projeto com estas qualificações.

\section{MATERIAL E MÉTODOS}

\section{1 Área de Estudo}

No município de Trairi, cidade costeira do litoral Oeste à $105 \mathrm{~km}$ da capital do Ceará, localizado entre as coordenadas $3^{\circ} 16^{\prime} 40^{\prime}$ ' S e $39^{\circ} 16^{\prime} 8^{\prime \prime} \mathrm{W}$, estão situadas duas comunidade praianas denominadas Flecheiras e Guajirú, que desenvolvem um projeto de iniciativa 
privada em parceria com o Instituto Terramar de Pesquisa e Assessoria de Pesca e apoio financeiro da Petrobras, por meio Programa Petrobras Ambiental (Figura 11. O clima é classificado como tropical quente semiárido brando com inverno seco e verão chuvoso, pluviosidade média anual de $1.588 \mathrm{~mm}$ concentrada nos meses de janeiro a abril e temperatura média anual de $26^{\circ} \mathrm{C}$ a $28^{\circ} \mathrm{C}$ (IPECE, 2014). Trairi possui uma população de 51.422 habitantes em uma área de 924,56 $\mathrm{km}^{2}$, situada em relevo de tabuleiro pré-litorâneo com altitude de 18 m (IPECE, 2014), abriga vegetação denominada de Complexo Vegetacional da Zona Litorânea e Floresta Perenifólia Paludosa Marítima (FIGUEIREDO, 1997).

O projeto intitulado "Algas: Cultivando Sustentabilidade"iniciou em 1997, mas teve visibilidade maior a partir de 2002 quando o Instituto Terramar apoiou o grupo de moradores locais que cultivava algas silvestres na região. A partir de então o cultivo passou a ser manejado e, as algas desidratadas e embaladas passaram a ser vendidas para indústrias Alimentícias, Farmacêuticas e Cosméticas do mercado nacional e internacional. Antes a população realizava a coleta de algas nos recifes naturais da região, mas era uma atividade extrativista sem reposição e que prejudicava diretamente o ecossistema local (www.algascultivandosustentabilidade.net).

No Brasil a produção de macroalgas e de algumas espécies de peixe começam a ganhar destaque, mas ainda com um baixo volume nacional em comparação com o cultivo de camarões e moluscos da zona costeira (PEREIRA; ROCHA, 2015). Contudo, em oposição aos hábitos exploratórios realizados anteriormente de maneira informal, o avanço de técnicas de cultivo, resultante do progresso das ciências tem auxiliado os processos produtivos (ASSAD; BURSTZYN, 2000). A sustentabilidade depende de projetos concebidos para gerar empregos, distribuir riqueza, harmonizar o modo de produção com a cultura local e melhorar a qualidade de vida das populações locais (CLARO; CLARO; AMÂNCIO 2008). Percebe-se então que o projeto "Algas: Cultivando Sustentabilidade" foi concebido com base nos pressupostos de sustentabilidade, diferente da maioria da produção de macroalgas no Brasil que é majoritariamente extrativista, principalmente, entre o litoral do Ceará e da Paraíba (OLIVEIRA, 2002).

Na sede do projeto em Flecheiras tambêm funciona um Centro de Educação Ambiental que realiza atividades voltadas para os moradores e estudantes da escola local, como por exemplo, as oficinas de Edução Ambiental realizadas em Novembro de 2011 na Escola de Ensino Médio Fortunato Severiano da Costa, com o ob- jetivo de apresentar aos estudantes as reflexões e pequisas sistematizadas pelo projeto, além de receber visitas de grupos que queiram entender e conhecer melhor o projeto.

\subsection{Coleta e análise dos dados}

Para avaliar a influência do projeto "Algas: Cultivando Sustentabilidade" comparamos a sensibilização ambiental dos estudantes das escolas: Ensino Médio Raimundo Nonato Ribeiro (EA) localizada na sede do município de Trairi e Ensino Médio Fortunato Severiano da Costa (EB) situada na localidade de Flecheiras onde existe o projeto "Algas: Cultivando Sustentabilidade".

Foram selecionados para a pesquisa 35 alunos da EA e 33 alunos da $\mathrm{EB}$, pertencentes às turmas de $3^{\circ}$ ano do ensino médio, por serem as turmas que apresentavam a maior quantidade de estudantes residentes na localidade e por estarem no último ano do ensino básico. Para a coleta e compartilhamento das informações os alunos foram convidados a assinar o termo de consentimento livre e esclarecido, e foi reservado o direito de desistência em qualquer momento da pesquisa, bem como o anonimato, como recomendado pela resolução 196/96, do Comitê de Ética em Pesquisa (SAÚDE, 2008).

Como instrumento de coleta de dados, utilizamos um questionário com 13 (treze) questões objetivas, adaptado de Bertolini e Possamai (2005), que contêm questões elaboradas para verificar se os estudantes mantêm hábitos ecologicamente saudáveis e qual a consciência que eles mantêm acerca da promoção de um meio ambiente saudável.

Como encaminhamento metodológico, adotamos uma abordagem quantitativa, onde contabilizamos as respostas dos itens objetivos e quantificamos suas porcentagens (APOLINÁRIO, 2006).

A análise dos dados foi dividida em três tópicos: 1) o hábito diário dos estudantes, nas cinco primeiras questões; 2) o consumo responsável que os alunos apresentam, da sexta até a nona questão e 3) conhecimento de conceitos ambientais e de educação ambiental, abordada da décima até a décima terceira questão.

\section{RESULTADOS E DISCUSSÃO}

\subsection{Hábitos diários dos estudantes}

A população local descarta indiscriminadamente o lixo nas ruas, fato observado por uma breve caminhada nas imediações das escolas pesquisadas. Os alunos da escola B, localidade do projeto "Algas: Cultivando Sustentabilidade" se mostraram mais preocupados em relação ao destino do lixo doméstico, pois apenas $18 \%$ 


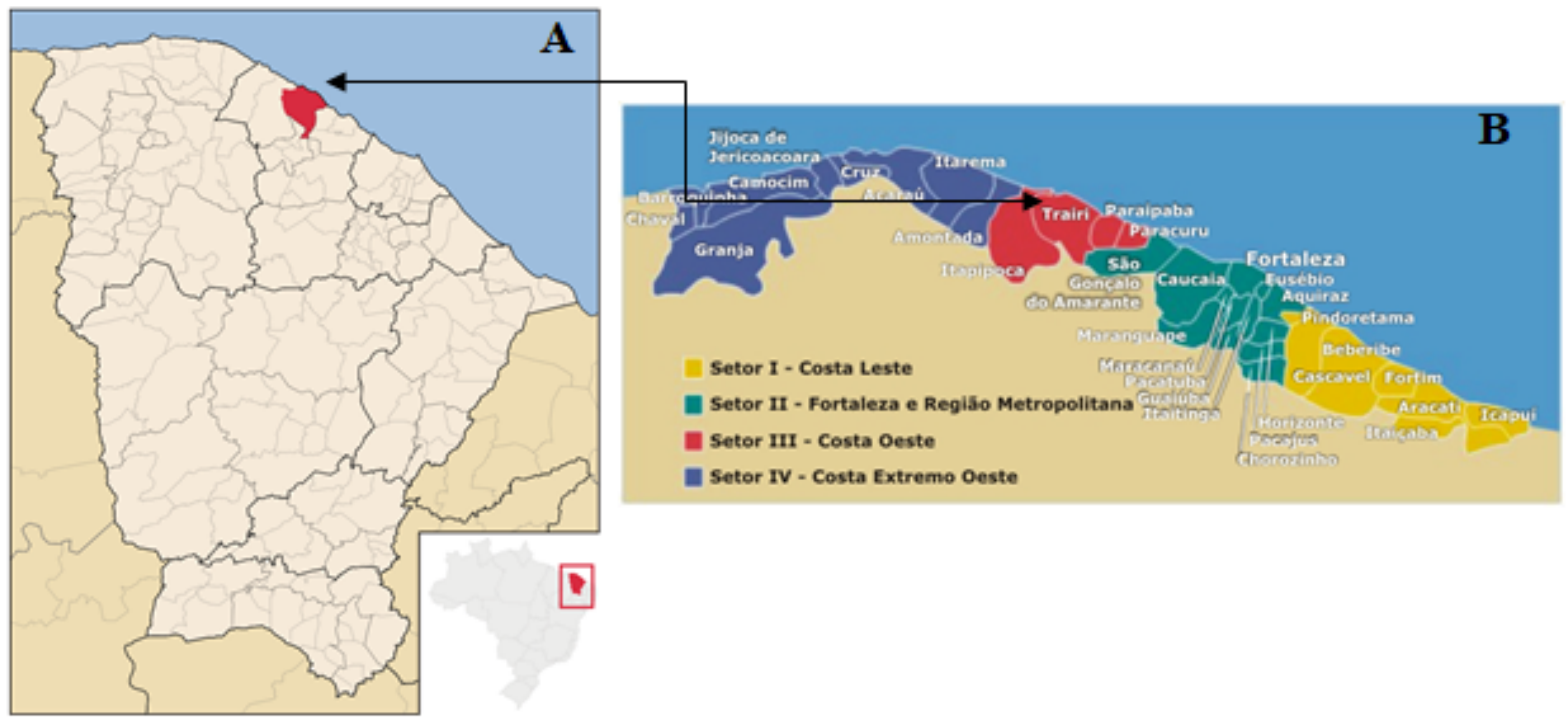

Fonte: <http://gerco.semace.ce.gov.br/gerco_ceara.asp $><$ https://pt.wikipedia.org/wiki/Trairi\#/media/File:Ceara_Municip_Trairi.svg >

afirmou que nunca pensou em como poderia reutilizalo, enquanto na escola A esse percentual foi de $22 \%$ (Figura 2A).

Os materiais que vão ao lixo nem sempre são inúteis, podem ser reaproveitados, mas para serem reciclados eles deverão ser selecionados de acordo com sua composição (GONÇALVES-DIAS, 2006, CARVALHO; GUERRA, 2015). Nesse contexto, o percentual de alunos que afirmou nunca separar o lixo foi maior na escola B (44\%) do que na escola A (35\%), aquela situada fora dos limites de atuação do projeto "Algas: Cultivando Sustentabilidade" (Figura 2B).

No entanto, todos os alunos da escola B (100\%), afirmaram que se preocupam em não jogar lixo na rua, nas frequências sempre (47\%), algumas vezes $(50 \%)$ e pouquíssimas vezes $(03 \%)$, enquanto na escola B esse percentual foi de $88 \%$ divididos nos itens sempre $(22 \%)$, algumas vezes $(50 \%)$ e pouquíssimas vezes (12\%). Os estudantes das duas escolas parecem se preocupar em manter o lixo fora das ruas, pois a poluição afetaria diretamente a pesca, o cultivo de algas marinhas e o aspecto visual da região que atrai muitos turistas. Um dos principais problemas que o lixo trás é decorrente da sua presença direta no ambiente. Esses materiais poluem e causam desastres como o entupimento de bueiros, desequilíbrio ecológico e doenças (MUCELIN; BELLINI, 2008).

Quando indagados sobre o desperdício de água e luz, a maioria dos alunos da escola B respondeu que tem essa preocupação $97 \%$ e $94 \%$, respectivamente, enquanto na escola A esses percentuais foram de $94 \%$ para medidas de prevenção do desperdício de água e luz (Figura 2C, 2D). Esses dados demonstram que os alunos das duas escolas parecem ter hábitos semelhantes tanto em relação à economia de água e luz quanto no que diz respeito ao destino dos resíduos domésticos e desperdício de materiais de uso cotidiano (Tabela 1 .

\subsection{Consumo responsável dos estudantes}

$\mathrm{O}$ percentual de alunos que assinalou nunca ter comprado produtos com embalagens recicladas ou que nunca pagou mais caro por um produto menos poluidor foi acima de 14\% nas duas escolas (Figura 3A, 3B). Em relação a compra de produtos com matéria-prima sustentável ou biodegradável, $100 \%$ dos alunos da escola $\mathrm{B}$ disseram que tem essa prática, enquanto na escola $\mathrm{A}$ esse percentual foi de $95 \%$ (Figura 3C). Os produtos fabricados com materiais mais rígidos são também os que demoram mais para serem decompostos naturalmente e por isso, muitas vezes os produtos com matérias-primas sustentáveis e biodegradáveis são preteridos na hora da compra (GONÇALVES-DIAS, 2006).

Sabemos que o valor monetário é um ponto forte para o consumo de um produto, mas uma estratégia para diminuir o impacto do consumo é utilizar os produtos ao máximo evitando que sejam precocemente descarta- 
Figura 2: Comportamento dos estudantes em relação ao manuseio de resíduos domésticos, água e luz. Escola A (Escola de Ensino Médio Raimundo Nonato Ribeiro, sede do município de Trairi-CE) e Escola B (Escola de Ensino Médio Fortunato Severiano da Costa, localidade de Flecheira, Trairi-CE).
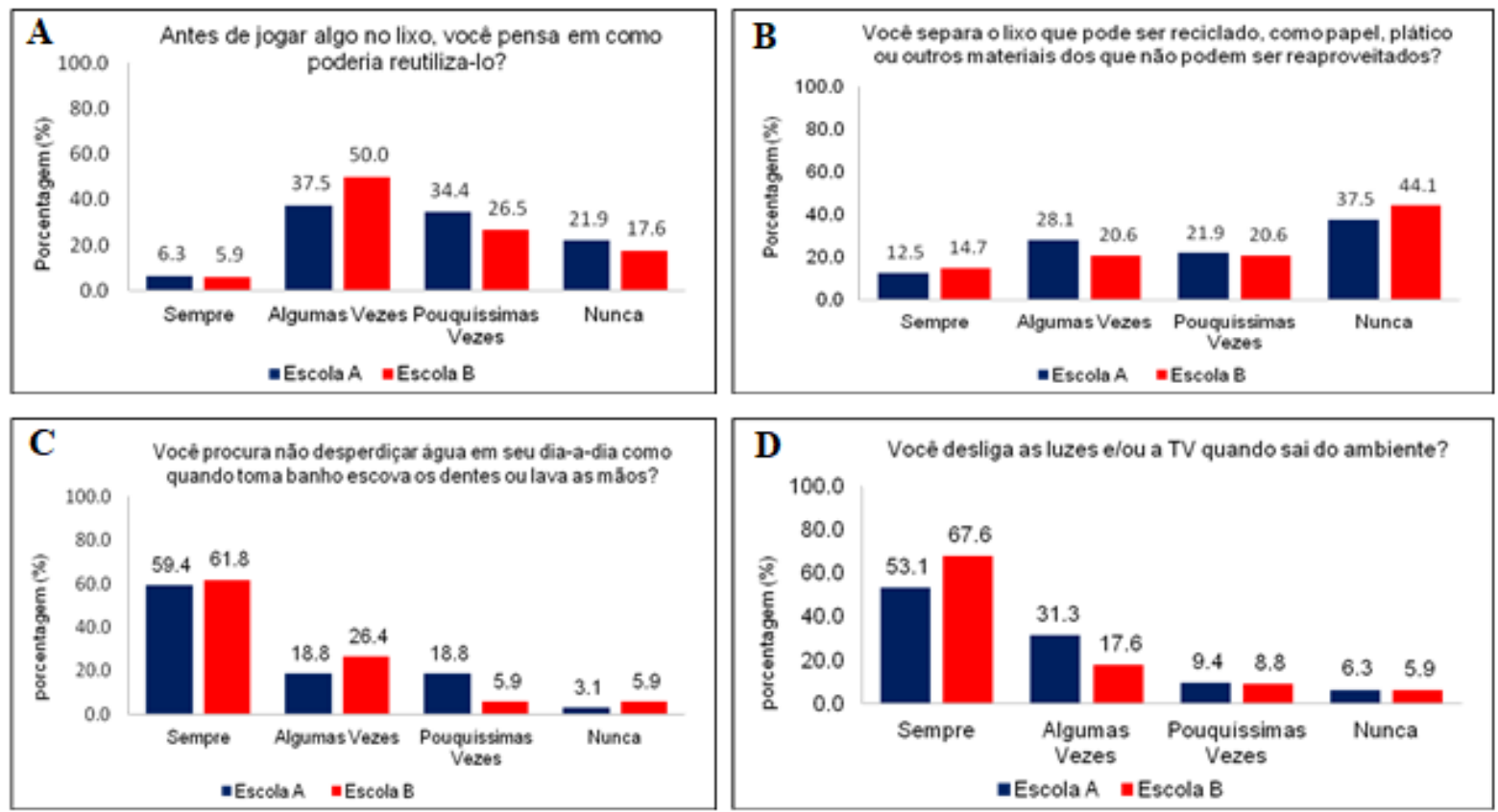

Fonte: Elaborada pelos autores.

Tabela 1: Comparação entre as porcentagens das respostas relacionadas ao hábito diário dos estudantes da Escola A (Escola de Ensino Médio Raimundo Nonato Ribeiro, sede do município de Trairi-CE) e Escola B (Escola de Ensino Médio Fortunato Severiano da Costa, localidade de Flecheira, Trairi-CE). Onde, $\mathrm{S}=$ Sempre, $\mathrm{AV}=$ Algumas Vezes e PV = Poucas Vezes.

\begin{tabular}{|c|c|c|c|c|}
\hline & $\begin{array}{c}\text { Escola A } \\
\text { (S, AV, PV) }\end{array}$ & $\begin{array}{c}\text { Escola A } \\
\text { (Nunca) }\end{array}$ & $\begin{array}{c}\text { Escola B } \\
(\mathbf{S , ~ A V , ~ P V ) ~}\end{array}$ & $\begin{array}{c}\text { Escola B } \\
\text { (Nunca) }\end{array}$ \\
\hline $\begin{array}{c}\text { Pensa em reutilizar } \\
\text { o lixo (Figura 1A) }\end{array}$ & $78 \%$ & $22 \%$ & $82 \%$ & $18 \%$ \\
\hline $\begin{array}{c}\text { Separa o lixo } \\
\text { (Figura 1B) }\end{array}$ & $65 \%$ & $35 \%$ & $56 \%$ & $44 \%$ \\
\hline $\begin{array}{c}\text { Preocupa-se em não } \\
\text { jogar lixo na rua }\end{array}$ & $88 \%$ & $12 \%$ & $100 \%$ & $00 \%$ \\
\hline $\begin{array}{c}\text { Não desperdiça água } \\
\text { (Figura 1C) }\end{array}$ & $97 \%$ & $03 \%$ & $94 \%$ & $06 \%$ \\
\hline $\begin{array}{c}\text { Não desperdiça luz } \\
\text { (Figura 1D) }\end{array}$ & $94 \%$ & $06 \%$ & $94 \%$ & $06 \%$ \\
\hline \multicolumn{5}{|c|}{ Fonte: Elaborada pelas autoras. } \\
\hline
\end{tabular}



PROJETO ALGAS, CULTIVANDO SUSTENTABILIDADE

dos e deixando-os fora do lixo por mais tempo. Nesse contexto, a maioria dos alunos da escola B (94\%) responderam que utilizam todas as folhas do caderno antes do descarte, valor superior ao da escola A que foi de $85 \%$ (Figura 3D). O produto mencionado neste item representa um entre tantos outros que fazem parte do consumo diário dos estudantes e, por isso, o modo como eles usam este produto é possivelmente um exemplo da conduta aplicada aos demais produtos do dia-a-dia.

\subsection{Conhecimentos de conceitos ambientais}

Indagamos se os estudantes entendem o conceito de "sustentabilidade" e "biodegradável". Registramos que $84 \%$ dos alunos da escola A acreditam saber o significado de sustentabilidade enquanto na escola B esse percentual foi de $80 \%$ (Figura 4A). Já em relação ao entendimento de material biodegradável, $78 \%$ dos alunos da escola A marcaram que sabem seu significado e na escola B esse percentual foi de 68\% (Figura 4B).

Apesar de multifacetado, pode-se definir de maneira resumida o desenvolvimento sustentável como aquela atividade que busca satisfazer as necessidades da geração presente sem comprometer as necessidades das gerações futuras (CLARO; CLARO; AMÂNCIO, 2008). A sustentabilidade é um conceito multifacetado, pois envolve um processo de mudança inspirado em novos valores estruturais, que deve ter a participação dos diferentes setores da sociedade, expressado por ações práticas que considerem a escala tempo-espaço, os limites ecológicos e ambientais, as características locais sociais e culturais e que busquem objetivos de desenvolvimento econômico (PEREIRA; ROCHA, 2015). Para estes autores, o cultivo de algas no Brasil ainda se configura como uma atividade frágil do ponto de vista da sustentabilidade.

Os estudantes das duas escolas têm interesse em questões ambientais, pois $97 \%$ e $100 \%$ dos alunos das escolas A e B, respectivamente, indicaram interesse em obter informações sobre preservação ambiental (Figura 5A). Os alunos da escola A, situada na sede do município de Trairi-Ce, afirmaram que a principal fonte de obtenção de conhecimentos ambientais é a escola (68\%), seguido de casa $(15,6 \%)$ e mídias e redes sociais $(15,6 \%)$, mas para os alunos da escola B, situada em Flecheiras, local do projeto "Algas: Cultivando Sustentabilidade", a escola teve uma influência equiparada a de mídias e redes sociais, ambas com 38,2\% (Figura 5B).

Um fator a ser levado em consideração é o crecimento do turismo na região, que resultou em um elevado número de jovens trabalhando na rede hoteleira, o quê tambêm pode explicar a forte interação com as mídias e redes sociais, já que estão ligados com as novas tecnologias e atualizações do mercado de trabalho. Além disso, os alunos da escola B que marcaram outras fontes citaram a "barraca das algas" como fonte de informação. Projetos de algicultura desenvolvidos no litoral cearense proporcionam alternativas socioeconômicas com melhora da renda familiar, preservam os recursos naturais e fortalecem a apropriação material e simbólica territorial pela comunidade (LIMA; CARNEIRO; MEIRELES, 2014).

De acordo com as Diretrizes Curriculares Nacionais para a Educação Ambiental, a Educação Ambiental como uma dimensão da educação é uma atividade que deve imprimir ao desenvolvimento individual um caráter social em sua relação com a natureza e com os outros seres humanos (BRASIL, 1999). Dessa forma, a educação ambiental partindo da escola deve ser instrumento para as mudanças em prol de estilos de vida sustentáveis (BRANCO; LINARD; SOUSA, 2011; WOLLMANN; SOARES; ILHA, 2015). Os elevados índices de alunos que citaram a escola como fonte de informação, especialmente na escola A, indicam que as escolas pesquisas parecem cumprir esse papel, de acordo com o estabelecido pelas diretrizes curriculares nacionais.

Diferente do esperado, não registramos uma sensibilização superior dos alunos da escola B (Fortunato Severiano da Costa - Flecheiras local do projeto "Algas: Cultivando Sustentabilidade") em relação aos alunos da escola A (Raimundo Nonato Ribeiro - sede do município de Trairi), refutanto a nossa hipótese. Isso se deve ao fato de que as porcentagens das respostas elencadas nos tópicos 1) hábito diário dos estudantes; 2) consumo responsável e 3) conhecimento de conceitos ambientais foram semelhantes.

Essa semelhança pode ser explicada de duas formas: 1) pode ser resultado de um trabalho de conscientização escolar superior na Escola A, visto que $69 \%$ dos alunos da escola A afirmaram que obtem informações ambientais na escola, em comparação com os $38 \%$ da escola B ou 2) pode ser reflexo de uma abrangência do projeto fora dos limites da comunidade. Não temos elementos empíricos suficientes para decidir entre uma ou outra explicação, mas podemos sugerir que as duas explicações são plausíveis e devem atuar conjuntamente, resultando em níveis de sensibilização ambiental elevados e semelhantes entre os alunos das duas escolas investigadas. 
Figura 3: Comportamento dos estudantes em relação ao manuseio de resíduos domésticos, água e luz. Escola A (Escola de Ensino Médio Raimundo Nonato Ribeiro, sede do município de Trairi-CE) e Escola B (Escola de Ensino Médio Fortunato Severiano da Costa, localidade de Flecheira, Trairi-CE).
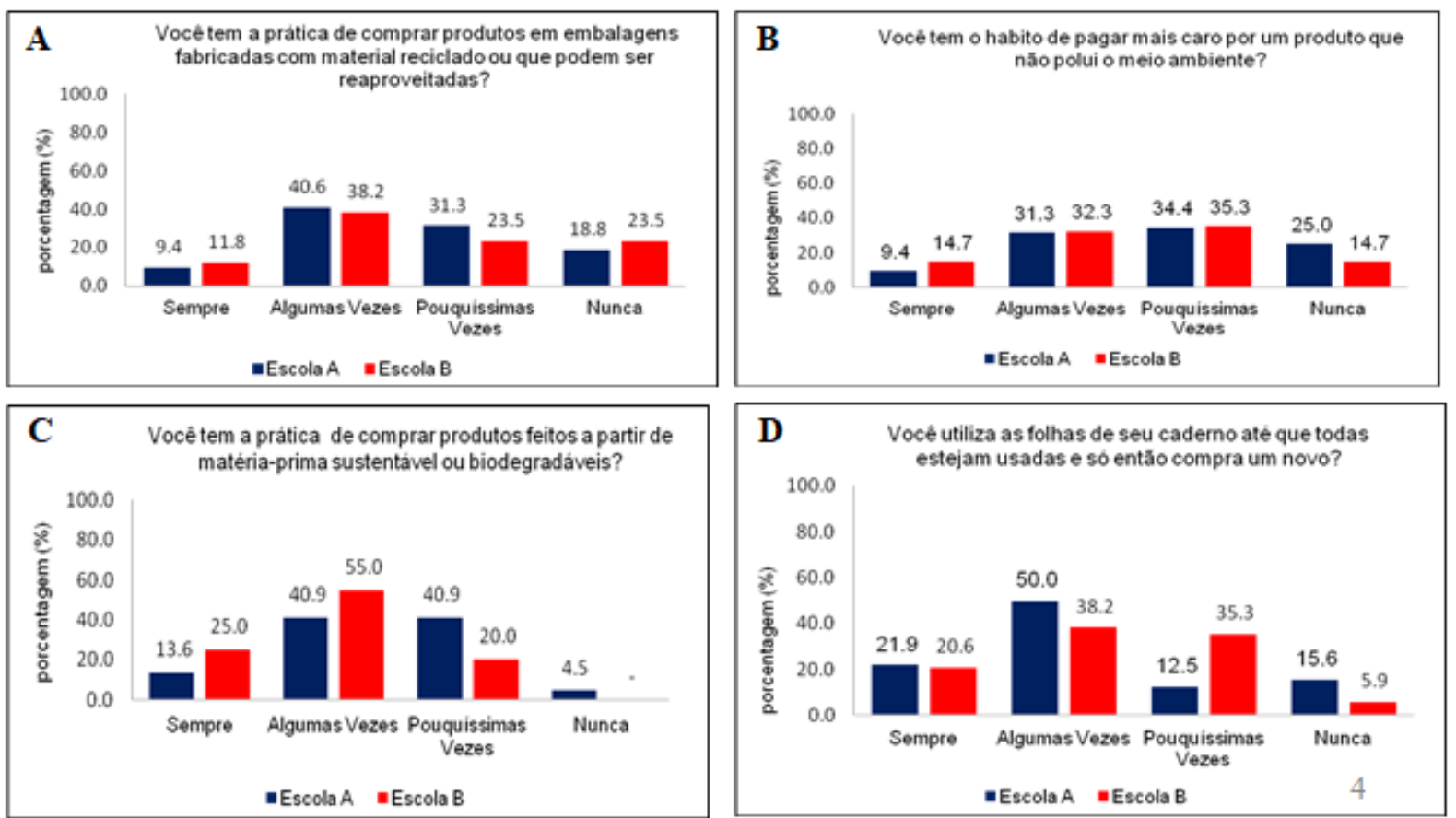

Fonte: Elaborada pelos autores.

Figura 4: Entendimento de sustentabilidade e biodegradável na visão dos estudantes. Escola A (Escola de Ensino Médio Raimundo Nonato Ribeiro, sede do município de Trairi-CE) e Escola B (Escola de Ensino Médio Fortunato Severiano da Costa, localidade de Flecheira, Trairi$\mathrm{CE})$.
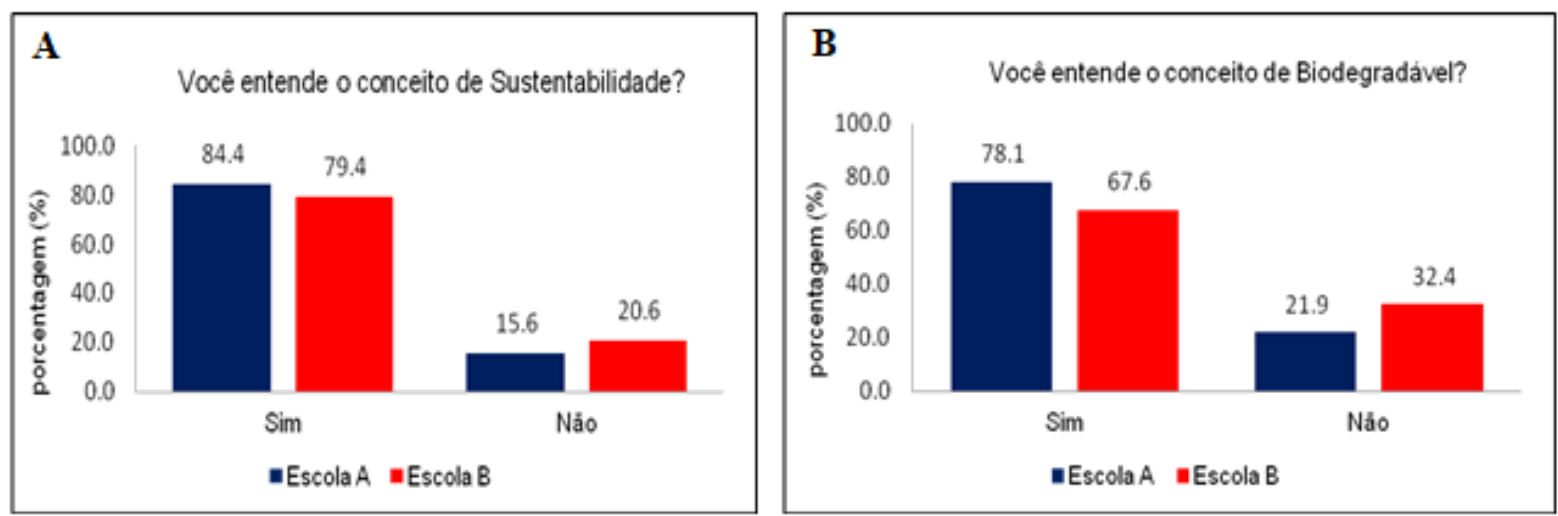

Fonte: Elaborada pelos autores. 
Figura 5: Interesse e fontes de informação dos estudantes em relação ao meio ambiente. Escola A (Escola de Ensino Médio Raimundo Nonato Ribeiro, sede do município de Trairi-CE) e Escola B (Escola de Ensino Médio Fortunato Severiano da Costa, localidade de Flecheira, Trairi-CE)
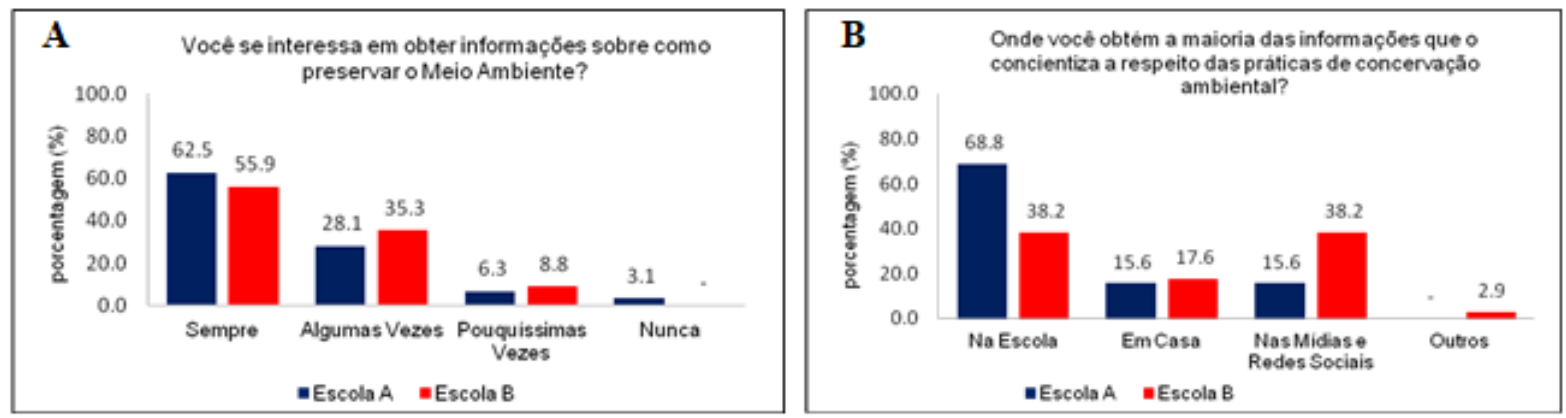

Fonte: Elaborada pelos autores.

\section{CONSIDERAÇÕES FINAIS}

Os alunos das duas escolas se mostraram sensíveis a questões ambientais relacionadas, por exemplo, ao destino de resíduos sólidos, ao uso responsável de água, luz e materiais cotidianos como os cadernos escolares. Isso indica que os estudantes saírão do ensino básico com uma mentalidade de responsabilidade e cuidado com a natureza que os cerca. Nessa pespectiva concordamos que a educação ambiental formal e informal, sozinhas, não são suficientes para mudar os rumos do planeta, mas contribuem para formar cidadãos mais conscientes, críticos, participativos e responsáveis pelo futuro do planeta (BRANCO; LINARD; SOUSA, 2011).

Respondendo ao questionamento inicial dessa investigação, podemos afirmar que sim, um projeto não governamental de atividades sustentáveis e com fundamentos na educação ambiental influencia positivamente a sensibilização ambiental de estudantes da escola local. Porém, essa influência não foi maior do que aquela desenvolvida pela escola, pois diferente do esperado os alunos da escola Fortunato Severiano da Costa (EB) situada na comunidade de Flecheira local de desenvolvimento do projeto "Algas: Cultivando Sustentabilidade", apresentaram sensibilização ambiental semelhante aquela apresentada pelos alunos da escola Raimundo Nonato Ribeiro (EA), situada na sede do município de Trairi-Ceará, onde não existe nenhum projeto com estas qualificações.

A escola da sede do município de Trairi, litoral oeste do Ceará parece influenciar na sensibilização ambiental dos jovens tanto quanto as ações informais desenvolvidas pela comunidade local. Isso demonstra que a Educação Ambiental é cada vez mais disseminada, tanto na esfera informal, quanto no âmbito da educação esco- larizada (REIS; SEMÊDO; GOMES, 2012), mas é na escola que ela tem sido especialmente difundida. Essa reflexão não pretende polarizar ações formais e informais como aquelas com "melhores" e "piores" resultados, pois acreditamos que apesar de desenvolvidas isoladamente, elas não são excludentes. Especialmente se entendermos que as ações de sensibilização ambiental, tanto no âmbito da educação formal (ROOS; BECKER. 2012) como no contexto informal (GOUVÊA, 2008), devem fomentar iniciativas que transcendam ao ambiente local e podem atingir tanto a comunidade local como comunidades mais afastadas nas quais residam alunos, professores e funcionários participantes diretamente das ações.

\section{REFERÊNCIAS}

APOLINÁRIO, F. Metodologia da Ciência: filosofia e prática da pesquisa. São Paulo: Ed Thomson, 2006.

ASSAD, L. T.; BURSTZYN, M. Aquicultura sustentável. In: VALENTI, W. C.; POLI, C. R.; PEREIRA, J. A.; R, B. J. (Ed.). Aquicultura no Brasil: bases para um desenvolvimento sustentável. Brasilia: Ministério da Ciência e Tecnologia. Conselho Nacional de Desenvolvimento Científico e Tecnológico, 2000. p. 33-70.

BERTOLINI, G. R. F.; POSSAMAI, O. Proposta de instrumento de mensuração do grau de conciência ambiental, do consumo ecológico e dos critérios de compra dos consumidores. Revista de Ciências \& Tecnologia, Piracicaba, v. 13, n. 25/26, p. 17-25, 2005.

BRANCO, A. F. V. C.; LINARD, Z. Ú. S. A.; SOUSA, A. C. B. Educação para o desenvolvimento sustentável 
INFLUÊNCIA DE UM PROJETO NÃO GOVERNAMENTAL NA EDUCAÇÃO AMBIENTAL FORMAL E INFORMAL: O CASO DO PROJETO ALGAS, CULTIVANDO SUSTENTABILIDADE

e educação ambiental. Conexões Ciência e Tecnologia, pesqueira e meio técnico-científico-informacional. Fortaleza, v. 5, n. 1, p. 25-31, 2011. REDE - Revista Eletrônica do PRODEMA, Fortaleza,

BRASIL. Política Nacional de Educação Ambiental. Lei $N^{o}$ 9.795, 27 de abril de 1999. 1999. v. 8 , n. 2, p. $35-49,2014$.

. Constituição 1988. Constituição da República Federativa do Brasil. Organização de Alexandre de Moraes. São Paulo: Ed Atlas, 2000.

CARVAlHO, A. G.; GUERRA, L. D. Ponto de inflexão no planejamento da gestão de resíduos sólidos urbanos: a superação da secundarização da questão socioambiental em campina grande - PB. Revista Movimentos Sociais e Dinâmicas Espaciais, Recife, v. 10, n. 1, p. 150-169, 2015.

CLARO, P. B. O.; CLARO, D. P.; AMÂNCIO,

R. Entendendo o conceito de sustentabilidade nas organizações. Revista Administração, São Paulo, v. 43, n. 4, p. 289-300, 2008.

COSTA, C. A. d.; COSTA, F. G. A. Educação como instrumento na construção da conciência ambiental. Nucleus, Ituverava, v. 8, n. 2, p. 21-40, 2011.

FIGUEIREDO, M. A. A cobertura vegetacional do ceará: Unidades fitoecológicas. In: Ceará. Atlas do Ceará. Edições IPLANCE. Fortaleza: , 1997. p. 28-29.

GONÇALVES-DIAS, S. L. F. Há vida após a morte: um (re) pensar estratégico para o fim da vida das embalagens. Gestão \& Produção, São Carlos, v. 13, n. 3, p. 463-474, 2006.

GOUVÊA, S. P. Microalgas do parque ecológico de são carlos, sp como base para materiais de educação ambiental: sensibilização para a preservação de ambientes aquáticos. Multiciência, Campinas, v. 9, n. 1, p. 28-37, 2008.

IPECE. Instituto de pesquisa e estratégia econômica do ceará. 2013. Perfil Básico Municipal - Trairi, Fortaleza: Governo do Estado do Ceará, p. 17, 2014.

KIST, A. C. F. Consciência e prática de Educação Ambiental: Uma análise a partir das matrizes teórica e epistemológica presentes em escolas estaduais de ensino fundamental de Santa Maria - RS. 136 p. Dissertação (Mestrado em Geografia) - Universidade Federal de Santa Maria, Santa Maria, 2010.

LIMA, A. P. S.; CARNEIRO, R. N.; MEIRELES, A. J. A. Ecossistema banco de algas e identidade territorial no município de icapuí/ce: comunidade tradicional

LUCCA, E. J.; BRUM, A. L. Educação ambiental: como implanta-la no meio rural. RAIMED - Revista de Administração IMED, Passo Fundo, v. 3, n. 1, p. 33-42, 2013.

MANO, E. B.; PACHECO, E. B. A. V.; BENELLI, C. M. C. Meio Ambiente, Poluição e Reciclagem. São Paulo: Ed Blucher, 2010.

MATOS, K. S. A. L. d. Educação Ambiental e Sustentabilidade. Fortaleza: Edições UFC, 2009.

MUCELIN, C. A.; BELLINI, M. Lixo e impactos ambientais perceptíveis no ecossistema urbano. Sociedade \& Natureza, Uberlandia, p. 111-124, 2008.

OLIVEIRA, E. C. Macroalgas marinhas da costa brasileira - estado do conhecimento, uso e conservação biológica. In: ARAUJO, E. L.; MOURA, A. N.; SAMPAIO, V. S. B. (Ed.). Biodiversidade, Conservação e Uso Sustentável da Flora do Brasil. Recife: Universidade Federal Rural de Pernambuco, 2002. p. 122-126.

PASSOS, M. G.; PRADO, F. P.; CASON, M. C.; BORTONCELLO, C. A. Sociologia e educação ambiental: Quando a sociedade começará a se preocupar com um futuro sustentável. Revista Brasileira de Educação Ambiental (RevBEA), Rio Grande, v. 8, n. 1, p. 100-113, 2014.

PEREIRA, L. A.; ROCHA, R. M. A maricultura e as bases econômicas, social e ambiental que determinam seu desenvolvimento e sustentabilidade. Ambiente \& Sociedade, São Paulo, v. 18, n. 3, p. 41-54, 2015.

REIS, L. C. L.; SEMÊDO, L. T. A. S.; GOMES, R. C. Concientização ambiental: da educação formal a não formal. Revista Fluminense de Extensão Universitária, Rio de Janeiro, v. 2, n. 1, p. 47-60, 2012.

ROOS, A.; BECKER, E. L. S. Educação ambiental e sustentabilidade. Revista Eletrônica em Gestão,

Educação e Tecnologia Ambiental, Santa Maria, v. 5, n. 5, p. 857-866, 2012.

SAÚDE. Manual operacional para comitês de ética em pesquisa. 4. ed. : Ed Ministério da Saúde, 2008. $138 \mathrm{p}$. 
INFLUÊNCIA DE UM PROJETO NÃO GOVERNAMENTAL NA EDUCAÇÃO AMBIENTAL FORMAL E INFORMAL: O CASO DO PROJETO ALGAS, CULTIVANDO SUSTENTABILIDADE

WOLLMANN, E. M.; SOARES, F. A. A.; ILHA, P. V.

As percepções de educação ambiental e meio ambiente de professoras das séries finais e a influência destas em suas práticas docentes. Revista Brasileira de Pesquisa

em Educação em Ciências, Minas Gerais, v. 15, n. 2, p. 387-405, 2015. 